San Jose State University

SJSU ScholarWorks

January 2010

\title{
Racial differences in the association between partner abuse and barriers to prenatal health care among asian and native Hawaiian/ other Pacific Islander women
}

\author{
Van M. Ta Park \\ San Jose State University, van.ta@sjsu.edu \\ D. Hayes \\ Hawai'i Department of Health, Honolulu, HI
}

Follow this and additional works at: https://scholarworks.sjsu.edu/healthsci_rec_pub

Part of the Medicine and Health Sciences Commons

\section{Recommended Citation}

Van M. Ta Park and D. Hayes. "Racial differences in the association between partner abuse and barriers to prenatal health care among asian and native Hawaiian/other Pacific Islander women" Maternal \& Child Health Journal (2010): 350-359.

This Article is brought to you for free and open access by the Health Science and Recreation at SJSU

ScholarWorks. It has been accepted for inclusion in Faculty Publications by an authorized administrator of SJSU

ScholarWorks. For more information, please contact scholarworks@sjsu.edu. 


\section{Racial Differences in the Association Between Partner Abuse and Barriers to Prenatal Health Care among Asian and Native Hawaiian/Other Pacific Islander Women}

*Van M. Ta, Ph.D., M.P.H.

Assistant Professor

Office of Public Health Studies

University of Hawai'i at Mānoa

1960 East-West Rd., D104AA

Honolulu, HI 96822

Phone: (808) 956-5767

Fax: (808) 956-5818

Email: vanta@hawaii.edu

Donald Hayes, M.D., M.P.H.

Epidemiologist, Maternal and Child Health

Family Health Services Division

Hawai'i Department of Health

3652 Kilauea Avenue

Honolulu, HI 96816

Phone: (808) 733-8360

Fax: (808) 733-8369

Email: don.hayes@doh.hawaii.gov

*Corresponding author 


\begin{abstract}
Objectives. Prenatal health care (PNC) is associated with positive maternal and infant health outcomes. There is limited knowledge regarding Native Hawaiians/Other Pacific Islanders (NHOPI) and Asian women’s access to PNC especially among those with partner abuse (PA) experience. The objectives of this paper were to 1) describe and examine factors associated with PNC access barriers among mothers, by race; and, 2) determine the association between PA and PNC access, by race. Methods. We analyzed 2004-07 data from Hawai‘i’s Pregnancy Risk Assessment Monitoring System $(n=7,158)$. The outcome is $\geq 1$ experience with a PNC access barrier. PA is experience with physical violence from a partner. Descriptive statistics, and bivariate and multivariate logistic regression analyses stratified by race were conducted. Results. The respondents included 35.7\% NHOPI, 37.4\% Asian, 20.1\% White and 6.6\% Other. More than 6\% experienced PA, and 25.9\% reported $\geq 1$ PNC access barrier. Experience with PA was significantly associated with NHOPI and Asians reporting $\geq 1$ barrier to accessing PNC, but was non-significant with Whites. Conclusions. Programs should address barriers to accessing PNC, and target NHOPI and Asian mothers with PA experience to reduce the healthcare disparity and improve quality of life.
\end{abstract}




\section{INTRODUCTION}

According to the U.S. Census, there were nearly 15.2 million Asians in 2007 and more than one million Native Hawaiians/Other Pacific Islanders (NHOPI) (1). Asians and NHOPI are heterogeneous populations that have diverse languages, cultures, and period of residences in the U.S. (2, 3). In 2000, there were more than 1.2 million persons residing in Hawai’i (4) including the following major racial groups: NHOPI (9.4\%), Asians (41.6\%), and Whites (24.3\%).

Although it is widely known that the receipt of prenatal health care (PNC), “medical attention given to the expectant mother and her developing baby” (5), is associated with positive health outcomes among the mothers and babies, approximately one million women in the U.S. did not receive adequate PNC in 2006. Lack of PNC has severe consequences including preterm labor, low birth weight, and infant death (5-23).

Furthermore, for a number of mothers access to PNC may be challenging due to an array of factors $(24,25)$. Examples of common PNC barriers include lack of transportation, lack of health insurance, lack of childcare, an “ambivalence of being pregnant," a belief that PNC was unimportant with successive pregnancies, difficulty getting an appointment, and their negative experiences with prior PNC (e.g. poor treatment from individuals at the clinic). Experiences with PNC barriers differ by race, however. Compared to White mothers, more Hispanic and Black mothers report lack of transportation, lack of health insurance, ambivalence with being pregnant, and negative experiences with prior PNC as PNC barriers.

In another study, Yu et al. found low use of PNC among Asian Americans are associated with being single, being young, and having low educational attainment (26). Also, the lowest use of PNC is in Korean and Vietnamese Americans. In another study, Kogan et al. found comparable socio-demographic factors associated with PNC use in White, Native Hawaiian, 
Japanese and Filipino mothers; however, compared to other ethnic groups, Native Hawaiians have the highest proportions with no or inadequate PNC use.

In addition to these PNC barriers, a mother's experience of partner abuse (PA), which occurs "when a person hurts or tries to hurt a partner by hitting, kicking, burning, or other physical force (27),” also serves as a barrier to PNC. For example, Parker et al. found that among teenage pregnant women, 24\% with PA experience delayed PNC compared to 9\% with no PA experience (28). In another study, Dietz et al. found that mothers who experienced physical violence from their partners were significantly more likely to have delayed PNC compared to mothers with no physical violence experience (29).

The relationship between PA and maternal/child health outcomes is well documented. For example, a 2001 systematic review and meta-analysis paper reported that women who were abused during their pregnancy were 1.4 times more likely to have a low birth weight baby compared to non-abused women (30). Another review paper found the prevalence of violence to be as high as $20 \%$ during pregnancy (31). Another study found that women experiencing PA both before/during pregnancy were at risk for numerous poor health outcomes; however, Asians and NHOPI were lumped together and the relationship between PA and PNC access problems was not examined (32). Prior studies have also found that women who experience PA are at a significantly increased risk of having poorer mental health compared to women with no PA experience (33-37) and, the psychological consequences are typically long-term and debilitating (38).

There is a literature gap regarding abused, Asian and NHOPI mothers' PNC experiences. Although there are a few studies that have examined PNC among certain Asian groups and Native Hawaiians as previously mentioned (26, 32, 39, 40), none to the authors' knowledge have 
directly evaluated the association between PA experience and PNC access barriers. Given the importance of PNC to maternal/infant health and PA being a predictor of poor health outcomes, it is vital to also determine the role of PA in accessing PNC particularly among understudied and rapidly growing Asian and NHOPI populations.

The study's specific aims were to 1) describe and examine factors associated with PNC access barriers among mothers, by race; and, 2) determine the role of PA in accessing PNC among mothers, by race. The study’s findings addresses a specific focus area goal of Healthy People 2010: to improve the health and well-being of women, infants, children, and families (41).

\section{METHODS}

Data source. We analyzed de-identified data from Hawai‘i’s 2004-07 Pregnancy Risk Assessment Monitoring System (PRAMS), a project of the Centers for Disease Control and Prevention and state health departments. PRAMS is an ongoing state-and population-based surveillance system that monitors selected maternal behaviors and experiences among women before, during, and after a pregnancy that resulted in a live birth. Of the 7,233 women who completed the survey, 57 women were excluded from the analyses because they did not respond to the PNC barriers question and 18 women were excluded due to missing racial data. The final sample was 7,158 .

Response rates. The overall response rate was $76.7 \%$, of which $78.0 \%$ completed in the mail phase (73.1\% of all mail completers did so in the first mailing), and the remaining $22.0 \%$ in the phone phase. The proportions of respondents by year were $24.6 \%$ (2004), $24.1 \%$ (2005), $25.5 \%$ (2006), and 25.8\% (2007).

Dependent variable. Respondents were provided with a list of problems that "some women can have getting PNC," and response categories of yes/no. The following is the list of 
barriers to accessing PNC (and for the purpose of our study, they are grouped into specific categories):

Logistical:

1) I couldn't get an appointment when I wanted one.

2) I had no way to get to the clinic or doctor's office.

3) I couldn't take time off from work.

4) I had no one to take care of my children.

5) I had too many other things going on.

Financial/Health Insurance:

6) I didn't have enough money or insurance to pay for my visits.

7) The doctor or my health plan would not start care as early as I wanted.

8) I didn't have my Medicaid or Quest card.

Personal:

9) I didn’t want anyone to know I was pregnant.

\section{Independent variables.}

Partner abuse is defined as experience with physical violence from a current/former husband/partner before and/or during pregnancy. Respondents were asked if the following occurred during "the 12 months before you got pregnant" and/or their "most recent pregnancy": 1) Did an ex-husband or ex-partner push, hit, slap, kick, choke, or physically hurt you in any other way? (yes/no); and, 2) Were you physically hurt in any way by your husband or partner? (yes/no).

Socio-demographics. Mothers were asked to self-report their race/ethnicity; race is categorized as White, Asian, NHOPI, and Other. Maternal age is a continuous variable. The 
household income categories included: < \$10,000, \$10,000-24,999, \$25,000-49,999, and $\$ 50,000+$. The education categories included: high school education or less, some college or more, and college education or more. The marital status categories included “married” and "other." The regional categories included urban and rural. The counties for maternal residence were Hawai‘i, Honolulu, Kaua‘i, and Maui.

Respondents were asked, “Are you currently in school or working outside the home?” Employment/school is a binary variable (yes/no). Health insurance status was dichotomized to having insurance (including Quest Medicaid) and being uninsured.

Substance use. Respondents were asked, “Did you use any of these drugs when you were pregnant?” (yes/no). The types of drugs included prescription drugs, marijuana/hashish, amphetamines, cocaine/heroin, tranquilizers/hallucinogens, and sniffing gasoline/glue/hairspray/other aerosols.

Data Analysis. We computed weighted descriptive statistics using the svy suite from Stata version 10.0 (42). Our analyses accounted for the complex survey design to calculate appropriate standard error estimates. Bivariate/multivariate logistic regressions of experience with at least one PNC barrier (yes; no) by race were conducted. Differences in the odds ratio (OR) of PA were examined with sequential modeling for each racial group in the adjusted analyses.

Human Subjects Protection. This study was approved by the Committee on Human Research at the University of Hawai'i at Mānoa. A data sharing agreement was completed with the Hawai`i PRAMS program within the Hawai`i State Department of Health.

\section{RESULTS}


Descriptive Analyses (Table 1). The weighted percentage of the respondents by race were 35.7\% NHOPI, 37.4\% Asian, 20.1\% White and 6.6\% Other. The mean age of the mothers was 28.0 years, nearly two-thirds were married, less than half were employed/in school, and the majority had public/private health insurance. Nearly 18\% had an annual household income of less than $\$ 10,000,23.2 \%$ of $\$ 10,000-24,999,25.5 \%$ of $\$ 25,000-49,999$, and $33.5 \%$ of $\$ 50,000$ or more. More than $25 \%$ had a college or more education, $25.4 \%$ some college or more, and $49.1 \%$ high school or less. Most of the mothers resided in urban areas and in Honolulu County. Less than $3 \%$ of the mothers reported using illicit drugs during pregnancy.

The proportion of mothers who reported PA experience was $6.3 \%$. Nearly $26 \%$ of the mothers reported at least one PNC access barrier including $11.1 \%$ who reported multiple barriers. The mean number of PNC visits was 11.1, and the mean number of PNC access barriers was 0.46 . Nearly one in ten mothers reported that they could not get an appointment when they wanted one. One in 20 mothers reported that they a) did not have enough money or insurance to pay for their PNC visits, and, b) had too many things going on. More than one in 25 mothers reported that a) their doctor/health care plan would not start care as early as they had wanted, and, b) they did not have their Medicaid/Quest card. Nearly one in 25 mothers reported they a) could not take time off of work, and, b) did not want anyone to know that they were pregnant. Less than one in 25 mothers reported they a) had no way to get to the clinic/doctor's office, and, b) had no one to take care of their children. There were significant racial differences for all characteristics described.

Bivariate Analyses (Table 2). For Asian mothers, the odds of experiencing at least one PNC access barrier were 2.3 times higher for those having experience with PA (vs. none), 4.1 times higher for those without health insurance (vs. with), 1.6 times higher for those having a 
high school or less education (vs. college or more), 1.8-4.3 times higher for those having an annual household income under $\$ 50,000$ (vs. $\$ 50,000$ or more), 2.0 times higher for those who are not married (vs. married), and 4.0 times higher for those who use illicit substances (vs. not). The odds ratio for experience with at least one PNC access barrier associated with a 1-year increase in age was 0.95 among White mothers. Among Asian mothers, the odds ratio for experience with at least one PNC access barrier was 0.83 for those who are not employed or in school (vs. are).

For NHOPI mothers, the odds of experiencing at least one PNC access barrier were 3.4 times higher for those having experience with PA (vs. none), 1.8 times higher for those without health insurance (vs. with), 1.9 times higher for those having a high school or less education (vs. college or more), 1.6 times higher for those having some college or more (vs. college or more), 1.6-3.4 times higher for those having an annual household income under $\$ 50,000$ (vs. $\$ 50,000$ or more), 2.4 times higher for those who are not married (vs. married), and 2.3 times higher for those who use illicit substances (vs. not). Among NHOPI mothers, the odds ratio for experience with at least one PNC access barrier associated with a 1-year increase in age was 0.96. Among NHOPI mothers, the odds ratio for experience with at least one PNC access barrier was 0.72 for those who are not employed or in school (vs. are).

For White mothers, the odds of experiencing at least one PNC access barrier were 2 times higher for those having experience with PA (vs. none), 2.6 times higher for those without health insurance (vs. with), 1.6 times higher for those having a high school or less education and 1.4 times higher for those with some college or more, and 1.6-3.7 times higher for those having an annual household income under $\$ 50,000$ (vs. $\$ 50,000$ or more). The odds ratio for experience 
with at least one PNC access barrier associated with a 1-year increase in age was 0.96 among White mothers.

For “other race” mothers, the odds of experiencing at least one PNC access barrier were 2.5 greater for those without health insurance (vs. with), and 2.7 times greater for those having some college education or more (vs. college or more). Region and county of residence were not significantly associated with experience of at least one PNC barrier for any racial group.

Multivariate Analyses. Table 3 shows that for all sequential models (Models 2-7), experience with PA remains a significant factor associated with experience with at least one PNC barrier among Asian, NHOPI and "other race” mothers, but not for White mothers. After adjusting for age, marital status, education, household income, employment/school status, health insurance, maternal residence, and illicit drug use (Model 7), experience with PA was significantly associated among Asian (OR= 1.64, 95\% CI: 1.05, 2.55), NHOPI (OR= 1.52, 95\% CI: 1.05, 2.18), and “other race” (OR=3.10, 95\% CI: 1.23, 7.81) mothers reporting at least one barrier to accessing PNC, but the association was non-significant among White mothers (OR= 1.46, 95\% CI: 0.73, 2.94). Figure 1 provides a pictorial illustration of the unadjusted (Model 1) and adjusted (Model 7) models.

\section{DISCUSSION}

More than 6\% of mothers reported PA experience, and more than one in four at least one PNC access barrier. The major barriers to accessing PNC include two of the three financial/health insurance barriers (e.g. not have enough money or insurance to pay for their PNC visits; the mothers' doctor/health care plan would not start care as early as they had wanted), and three of the five logistical barriers (e.g. not having a way to get to the clinic/doctor's office, not getting an appointment when they wanted one and not having any one 
to take care of their children). In the bivariate analyses, White, Asian and NHOPI mothers had similar racial-specific factors that were significantly associated with PNC access barriers including experience with PA, no health insurance, having less than a college education, and having an annual household income of less than $\$ 50,000$. Other racial-specific factors that were significantly associated with experience with at least one PNC access barrier for Asian and NHOPI include not being married, and use of illicit substances. Younger age was found to be a risk factor among all racial groups, and not being employed or in school was found to be protective for Asian and NHOPI mothers. These identified risk factors are consistent with prior literature (26, 40, 43-47).

Adjusted analyses indicate that PA plays a significant role in Asian and NHOPI mothers’ having experience with at least one barrier to accessing PNC. Specifically, Asians with PA experience had a 1.6 times risk of experiencing at least one PNC access barrier compared to Asian mothers without PA experience; and, NHOPI had a 1.5 times risk of experiencing at least one PNC access barrier compared to NHOPI mothers without PA experience.

We found some similarities in the risk profiles between Asian and NHOPI mothers (Table 3), which warrant further research and discussion. The Asian and NHOPI may share similarities in some areas such as having higher proportions of mothers who are not married, employed/in school, and experience with PA compared to White mothers (Table 1), and perhaps such similarities have conventionally supported the practice of "lumping” Asian and NHOPI into one racial group in research and policy. Still, we caution against interpreting that the similarities found (Asian and NHOPI mothers experience similar race-specific factors that were significantly associated with PNC access barriers including experience with PA) means that they are the “same” because there is large heterogeneity in characteristics. For examples, compared to White 
mothers, there were higher proportions of Asian mothers but lower proportions of NHOPI mothers with a household income of $\$ 50,000$ or more. Also, nearly two-thirds of White and Asian mothers have a college (or more) education, which was more than $20 \%$ than that of NHOPI mothers. Future research should continue to investigate the between group differences as well as examine the within group differences.

Strengths. Hawai 'i PRAMS is an annual population-based survey that includes large proportions of Asians and NHOPI; therefore, it offers an opportunity to examine critical questions concerning maternal and infant health among understudied racial minorities. Our findings add to the little that is known about PNC and PA with such populations.

In our study, $35.7 \%$ of the mothers were NHOPI compared to $9.4 \%$ in Hawai'i. This difference is because the U.S. Census allows the respondent the option to select more than one race and the Census reports the multi-race numbers separately whereas the Hawai` $i$ birth certificate (which is linked to Hawai'i PRAMS) allows participants to enter several racial/ethnic groups. The data that is provided to Hawai`i PRAMS consolidates all the information and only reports one racial/ethnic group based on the respondent's selection. This is a problematic issue, particularly as national statistics are beginning to report out groups with 2 or more races. Hawai'i PRAMS is working with the Vital Statistics registrar on the technical details of the way race/ethnicity is coded to better inform this issue. The large sample size of Native Hawaiians in the sample allows precise estimates related to this population but the results are somewhat less generalizable to those who report other racial/ethnic groups.

Limitations. As with other secondary data analyses, this paper is limited to the information that was already collected. Also, PRAMS does not collect information on maternal country of birth, which may be an important factor in the association with PA and PNC. 
Although information on more detailed subgroups are available, the numbers were not large enough to allow a more detailed analysis of differences within the Asian or NHOPI population. Additionally, the PRAMS survey asks the mother about postpartum depression, but not about depression before/during pregnancy; postpartum depression was not included as a variable in the analyses because the temporal sequence did not match with the study's outcome (access to PNC).

Furthermore, the role of the severity and frequency of PA on the mothers' experience with PNC is unknown; however, future PRAMS surveys may be able to better determine this association by including questions related to this. Also, our findings are generalized to the noninstitutionalized, non-homeless, and English-speaking NHOPI and Asian American female population in Hawai' $i$. Moreover, our data are self-reported and subject to reporting biases where respondents may have desired to portray a positive image such that they may have understated the PA and experience with PNC barriers; however, future research may include external measures such as provider assessments of PA and reviewing patient records of PNC visits.

Study Implications/Next Steps. Our findings have important policy and programmatic implications. Future programs should address these financial/health insurance and logistical barriers. Domestic violence community-based organizations and local and state health departments may partner to discuss such potential programs including the feasibility of replicating successful PNC programs at other places. For example, a safety net hospital in Dallas sees pregnant women as walk-ins, and use “'Mom-mobiles,' which transport pregnant women to and from prenatal representatives" - these programs are associated with increased PNC visits (25). Other potential program ideas to address barriers to PNC include: (1) logistical barriers bus tokens/subsidies for taxi; on-site child care at certain heath facilities; extended clinic hours 
and weekend appointments (2) financial/health insurance barriers - subsidies to cover partial/full costs of a PNC visit (e.g. copayments); payment plans. Moreover, as part of routine PNC, women at risk for PA should be screened for potential access barriers and offered appropriate services to ensure consistent participation in PNC, a healthy pregnancy and quality of life.

This study found significant racial differences, which highlights the need for the training and provision of cultural competency among providers. PNC may be one of the few chances that battered pregnant women, particularly those who are a racial/ethnic minority women, may have to receive adequate care and attention (48).

The epidemic of PA among culturally diverse female populations calls upon the health care system to be equipped to, first, identify PA victims and, second, provide adequate health care to female victims of PA. As noted earlier, proper care including PNC, results in positive maternal and infant health outcomes. There is a great need, therefore, to screen for PA by primary care providers (49), prenatal care providers (50), and health-care providers in general (51-53).

Lastly, it is also vital to provide community education about the resources available to abused women. It is also important to work with community stakeholders such as domestic violence organizations, law enforcement, educators, and legislators to plan and implement macro-level policies that will ensure the safety of abused women as well as address the barriers identified in this study and other potential barriers to ensure appropriate and sufficient provision of quality services including PNC. 


\section{Acknowledgments}

We are grateful to Hawai'i PRAMS and the Family Health Services Division for providing us access to the PRAMS data. 


\section{REFERENCES}

1.Population Division, U.S. Census Bureau. Table 3: Annual Estimates of the Population by Sex, Race, and Hispanic Origin for the United States: April 1, 2000 to July 1, 2007 (NC-EST200703). In; 2008.

2.Reeves T, Bennett C. The Asian and Pacific Islander Population in the United States: March 2002. In. Washington, DC.: Current Population Reports, P20-540, U.S. Census Bureau; 2003. 3.Reeves TJ, Bennett CE. We the People: Asians in the United States. In: Census 2000 Brief, CENSR-17: U.S. Census Bureau; 2004.

4. U.S. Census Bureau. Hawaii Quick Facts. In: State and County Quick Facts; 2000. 5.Health Resources and Services Administration. A Healthy Start: Begin Before Baby's Born. Rockville: U.S. Department of Health and Human Services; 2008.

6.Curry MA, Perrin N, Wall E. Effects of abuse on maternal complications and birth weight in adult and adolescent women. Obstet Gynecol 1998;92(4 Pt 1):530-4.

7.Bullock LF, McFarlane J. The birth-weight/battering connection. Am J Nurs 1989;89(9):11535.

8.Murray JL, Bernfield M. The differential effect of prenatal care on the incidence of low birth weight among blacks and whites in a prepaid health care plan. N Engl J Med 1988;319(21):138591.

9.Luke B, Williams C, Minogue J, Keith L. The changing pattern of infant mortality in the US: the role of prenatal factors and their obstetrical implications. Int J Gynaecol Obstet 1993;40(3):199-212.

10.Gortmaker SL. The effects of prenatal care upon the health of the newborn. Am J Public Health 1979;69(7):653-60. 
11.Showstack JA, Budetti PP, Minkler D. Factors associated with birthweight: an exploration of the roles of prenatal care and length of gestation. Am J Public Health 1984;74(9):1003-8. 12.Greenberg RS. The impact of prenatal care in different social groups. Am J Obstet Gynecol 1983;145(7):797-801.

13.Coker AL, Sanderson M, Dong B. Partner violence during pregnancy and risk of adverse pregnancy outcomes. Paediatr Perinat Epidemiol 2004;18(4):260-9.

14.Berenson AB, Wiemann CM, Wilkinson GS, Jones WA, Anderson GD. Perinatal morbidity associated with violence experienced by pregnant women. Am J Obstet Gynecol 1994;170(6):1760-6; discussion 1766-9.

15.Dye TD, Tollivert NJ, Lee RV, Kenney CJ. Violence, pregnancy and birth outcome in Appalachia. Paediatr Perinat Epidemiol 1995;9(1):35-47.

16.Schei B, Samuelsen SO, Bakketeig LS. Does spousal physical abuse affect the outcome of pregnancy? Scand J Soc Med 1991;19(1):26-31.

17.Cokkinides VE, Coker AL, Sanderson M, Addy C, Bethea L. Physical violence during pregnancy: maternal complications and birth outcomes. Obstet Gynecol 1999;93(5 Pt 1):661-6. 18.Fernandez FM, Krueger PM. Domestic violence: effect on pregnancy outcome. J Am Osteopath Assoc 1999;99(5):254-6.

19.McFarlane J, Parker B, Soeken K. Abuse during pregnancy: associations with maternal health and infant birth weight. Nurs Res 1996;45(1):37-42.

20.Janssen PA, Holt VL, Sugg NK, Emanuel I, Critchlow CM, Henderson AD. Intimate partner violence and adverse pregnancy outcomes: a population-based study. Am J Obstet Gynecol 2003;188(5):1341-7. 
21.Covington DL, Hage M, Hall T, Mathis M. Preterm delivery and the severity of violence during pregnancy. J Reprod Med 2001;46(12):1031-9.

22.Sarkar NN. The impact of intimate partner violence on women's reproductive health and pregnancy outcome. J Obstet Gynaecol 2008;28(3):266-71.

23.Rachana C, Suraiya K, Hisham AS, Abdulaziz AM, Hai A. Prevalence and complications of physical violence during pregnancy. Eur J Obstet Gynecol Reprod Biol 2002;103(1):26-9.

24. Higgins P, Murray ML, Williams EM. Self-esteem, social support, and satisfaction differences in women with adequate and inadequate prenatal care. Birth 1994;21(1):26-33. 25.Regenstein M, Cummings L, Huang J. Barriers to Prenatal Care: Findings from a Survey of Low-income and Uninsured Women Who Deliver at Safety Net Hospitals. In. Washington, D.C.: National Public Health and Hospital Institute; 2005.

26.Yu SM, Alexander GR, Schwalberg R, Kogan MD. Prenatal care use among selected Asian American groups. Am J Public Health 2001;91(11):1865-8.

27.Centers for Disease Control and Prevention. Understanding Intimate Partner Violence Fact Sheet. In. Atlanta; 2006.

28.Parker B, McFarlane J, Soeken K, Torres S, Campbell D. Physical and emotional abuse in pregnancy: a comparison of adult and teenage women. Nurs Res 1993;42(3):173-8.

29.Dietz PM, Gazmararian JA, Goodwin MM, Bruce FC, Johnson CH, Rochat RW. Delayed entry into prenatal care: effect of physical violence. Obstet Gynecol 1997;90(2):221-4.

30.Murphy CC, Schei B, Myhr TL, Du Mont J. Abuse: a risk factor for low birth weight? A systematic review and meta-analysis. CMAJ 2001;164(11):1567-72.

31.Gazmararian JA, Lazorick S, Spitz AM, Ballard TJ, Saltzman LE, Marks JS. Prevalence of violence against pregnant women. JAMA 1996;275(24):1915-20. 
32.Silverman JG, Decker MR, Reed E, Raj A. Intimate partner violence victimization prior to and during pregnancy among women residing in 26 U.S. states: associations with maternal and neonatal health. Am J Obstet Gynecol 2006;195(1):140-8.

33.Danielson KK, Moffitt TE, Caspi A, Silva PA. Comorbidity between abuse of an adult and DSM-III-R mental disorders: evidence from an epidemiological study. Am J Psychiatry 1998;155(1):131-3.

34.Golding JM. Intimate Partner Violence as a Risk Factor for Mental Disorders: A MetaAnalysis. Journal of Family Violence 1999;14(2):99-132.

35.Plichta S. The effects of woman abuse on health care utilization and health status: a literature review. Womens Health Issues 1992;2(3):154-63.

36.Stark E, Flitcraft A. Killing the beast within: woman battering and female suicidality. Int J Health Serv 1995;25(1):43-64.

37.Norton IM, Manson SM. An association between domestic violence and depression among Southeast Asian refugee women. J Nerv Ment Dis 1992;180(11):729-30.

38.Basile K. Sexual Violence in the Lives of Girls and Women. In: Kendall-Tackett KA, editor. Handbook of Women, Stress, and Trauma. New York: Brunner-Routledge Taylor Francis Group; 2005. p. 101-122.

39.Morrow HW, Chavez GF, Giannoni PP, Shah RS. Infant mortality and related risk factors among Asian Americans. Am J Public Health 1994;84(9):1497-500.

40.Kogan MD, Alexander GR, Mor JM, Kieffer EC. Ethnic-specific predictors of prenatal care utilisation in Hawaii. Paediatr Perinat Epidemiol 1998;12(2):152-62.

41.Healthy People 2010: Maternal, Infant, and Child Health. In: U.S. Department of Health and Human Services, editor. Washington D.C. 
42.StataCorp. Stata Statistical Software: Release 10.0. In. College Station: Stata Corporation; 2007.

43.Espinosa L, Osborne K. Domestic violence during pregnancy: implications for practice. J Midwifery Womens Health 2002;47(5):305-17.

44.D'Ascoli PT, Alexander GR, Petersen DJ, Kogan MD. Parental factors influencing patterns of prenatal care utilization. J Perinatol 1997;17(4):283-7.

45.Joseph CL. Identification of factors associated with delayed antenatal care. J Natl Med Assoc 1989;81(1):57-63.

46.Mor JM, Alexander GR, Kogan MD, Kieffer EC, Hulsey TC. Determinants of prenatal care use in Hawaii: implications for health promotion. Am J Prev Med 1995;11(2):79-85.

47.Scupholme A, Robertson EG, Kamons AS. Barriers to prenatal care in a multiethnic, urban sample. J Nurse Midwifery 1991;36(2):111-6.

48.O'Campo P, Gielen AC, Faden RR, Kass N. Verbal abuse and physical violence among a cohort of low-income pregnant women. Womens Health Issues 1994;4(1):29-37.

49.Bauer HM, Rodriguez MA, Perez-Stable EJ. Prevalence and determinants of intimate partner abuse among public hospital primary care patients. J Gen Intern Med 2000;15(11):811-7. 50.Helton AS, McFarlane J, Anderson ET. Battered and pregnant: a prevalence study. Am J Public Health 1987;77(10):1337-9.

51.Morbidity and Mortality Weekly Report. Adverse Health Conditions and Health Risk Behaviors Associated with Intimate Partner Violence- United States, 2005. In; 2008.

52.Kubany ES, McKenzie WF, Owens JA, Leisen MB, Kaplan AS, Pavich E. PTSD among women survivors of domestic violence in Hawaii. Hawaii Med J 1996;55(9):164-5. 
53.Browne A. Violence against women by male partners. Prevalence, outcomes, and policy implications. Am Psychol 1993;48(10):1077-87. 


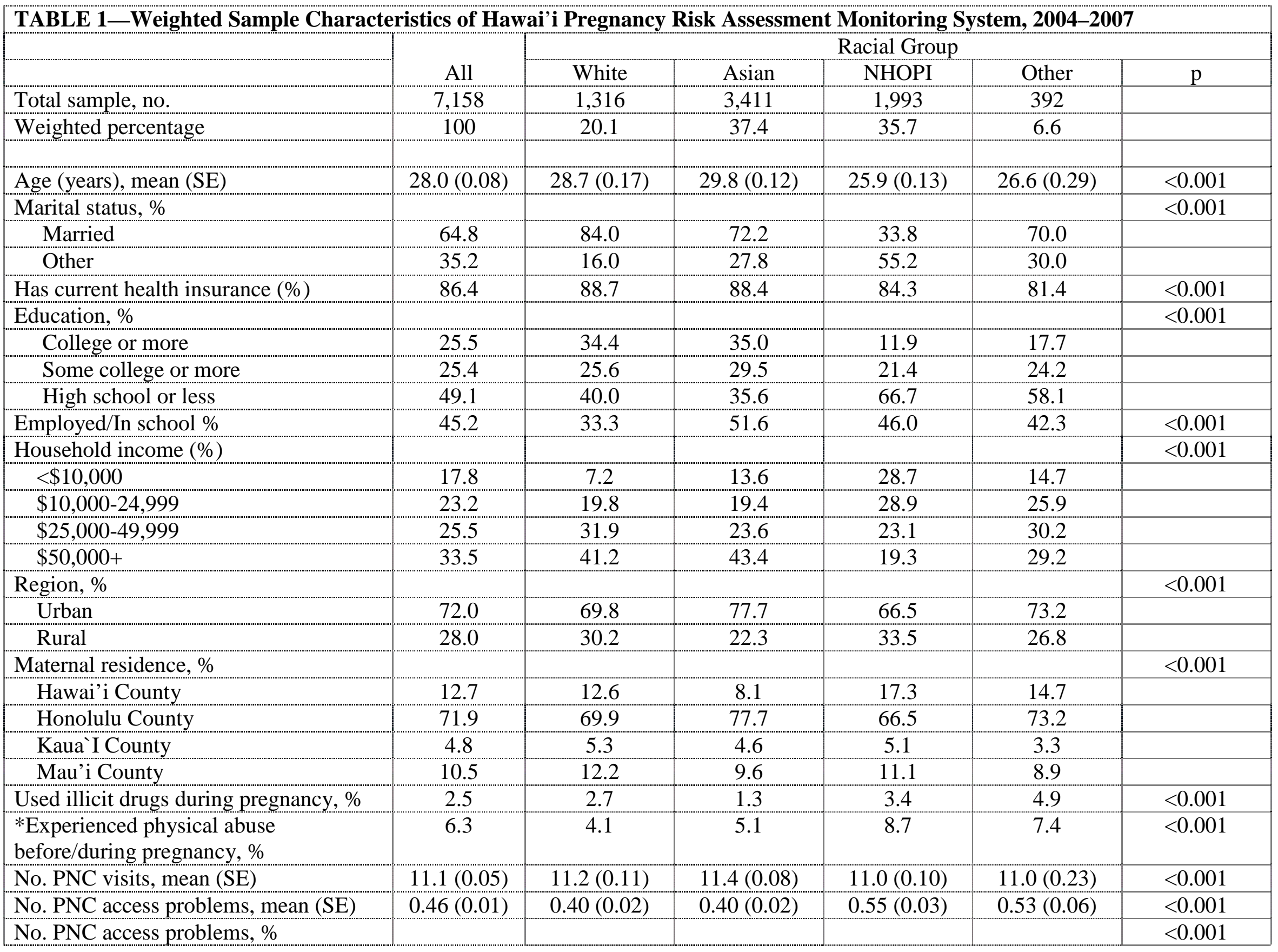




\begin{tabular}{|c|c|c|c|c|c|c|}
\hline 0 & 74.1 & 74.5 & 77.8 & 70.6 & 72.5 & \\
\hline $1+$ & 25.9 & 25.5 & 22.2 & 29.4 & 27.5 & \\
\hline \multicolumn{7}{|l|}{ PNC access problem \% } \\
\hline \multicolumn{7}{|l|}{ Logistical Barriers } \\
\hline $\begin{array}{l}\text { I couldn't get an appointment when I } \\
\text { wanted one. }\end{array}$ & 9.5 & 12.4 & 8.0 & 9.2 & 10.9 & $<0.001$ \\
\hline $\begin{array}{l}\text { I had no way to get to the clinic or } \\
\text { doctor's office. }\end{array}$ & 3.0 & 1.0 & 2.1 & 4.8 & 3.4 & $<0.001$ \\
\hline I couldn’t take time off from work. & 3.6 & 3.0 & 2.8 & 4.7 & 4.4 & $<0.01$ \\
\hline $\begin{array}{l}\text { I had no one to take care of my } \\
\text { children. }\end{array}$ & 2.7 & 2.9 & 1.9 & 3.3 & 3.0 & $<0.01$ \\
\hline I had too many other things going on. & 5.4 & 3.5 & 5.0 & 6.9 & 4.9 & $<0.01$ \\
\hline \multicolumn{7}{|l|}{ Financial/Health Insurance Barriers } \\
\hline $\begin{array}{l}\text { I didn't have enough money or } \\
\text { insurance to pay for my visits. }\end{array}$ & 5.0 & 3.4 & 4.6 & 6.2 & 6.1 & $<0.001$ \\
\hline $\begin{array}{l}\text { The doctor or my health plan would } \\
\text { not start care as early as I wanted. }\end{array}$ & 4.2 & 6.1 & 3.5 & 3.5 & 5.6 & $<0.001$ \\
\hline $\begin{array}{l}\text { I didn't have my Medicaid or Quest } \\
\text { card. }\end{array}$ & 4.2 & 2.3 & 5.0 & 4.2 & 3.7 & $<0.001$ \\
\hline \multicolumn{7}{|l|}{ Personal Barrier } \\
\hline $\begin{array}{l}\text { I didn’t want anyone to know I was } \\
\text { pregnant. }\end{array}$ & 3.9 & 1.9 & 3.4 & 5.7 & 3.2 & $<0.001$ \\
\hline
\end{tabular}

NOTE: Percentages might not equal 100\% due to rounding. "PNC”- prenatal healthcare. Physical abuse (from current/former husband/partner).

"NHOPI"- Native Hawaiian/Other Pacific Islander 
TABLE 2-Bivariate Analyses of Experience of Prenatal Health Care Access Barriers Among Mothers in Hawai'i, Stratified by Race, Pregnancy Risk Assessment Monitoring System, 2004-2007

\begin{tabular}{|c|c|c|c|c|}
\hline & $\begin{array}{c}\text { WHITE OR } \\
{[95 \% \mathrm{CI}]}\end{array}$ & $\begin{array}{c}\text { ASIAN } \\
\text { OR }[95 \% \text { CI] }\end{array}$ & $\begin{array}{c}\text { NHOPI } \\
\text { OR }[95 \% \text { CI }]\end{array}$ & $\begin{array}{c}\text { OTHER } \\
\text { OR }[95 \% \text { CI] }\end{array}$ \\
\hline $\begin{array}{l}\text { Experienced PA before/during pregnancy } \\
(\text { Yes } \dagger)\end{array}$ & $2.03[1.12,3.68]^{*}$ & $2.33[1.61,3.38]^{* * *}$ & $1.67[1.19,2.33]^{* *}$ & $2.76[1.23,6.19]^{*}$ \\
\hline Age & $0.96[0.94,0.98]^{* * *}$ & $0.95[0.94,0.97]^{* * *}$ & $0.96[0.94,0.97]^{* * *}$ & $0.99[0.95,1.03]$ \\
\hline \multicolumn{5}{|l|}{ Marital status (Married $\dagger$ ) } \\
\hline Other & $1.32[0.94,1.85]$ & $1.96[1.61,2.38]^{* * *}$ & $1.83[1.49,2.25]^{* * *}$ & $2.45[1.42,4.22]^{* * *}$ \\
\hline Current health insurance (Yes $\dagger$ ) & $2.60[1.81,3.74]^{* * *}$ & $4.07[3.19,5.21]^{* * *}$ & $3.08[2.38,3.99]^{* * *}$ & $1.15[0.70,1.90]$ \\
\hline \multicolumn{5}{|l|}{ Education (College or more $\dagger$ ) } \\
\hline Some college or more & $1.40[1.00,1.97]^{*}$ & $1.18[0.94,1.49]$ & $1.58[1.09,2.30]^{*}$ & $2.69[1.25,5.79]^{* *}$ \\
\hline High school or less & $1.62[1.20,2.20]^{* *}$ & $1.57[1.26,1.95]^{* * *}$ & $1.68[1.20,2.34]^{* *}$ & $1.90[0.94,3.84]$ \\
\hline Employed/In school (Yes $\dagger$ ) & $0.86[0.65,1.13]$ & $0.83[0.69,0.99]^{*}$ & $0.72[0.59,0.88]^{* *}$ & $0.89[0.55,1.43]$ \\
\hline \multicolumn{5}{|l|}{ Household income $(\$ 50,000+\dagger)$} \\
\hline$\$ 25,000-49,999$ & $1.58[1.15,2.18]^{* *}$ & $1.80[1.39,2.32]^{* * *}$ & $1.59[1.11,2.30]^{*}$ & $0.81[0.42,1.57]$ \\
\hline$\$ 10,000-24,999$ & $1.86[1.30,2.68]^{* * *}$ & $2.71[2.09,3.41]^{* * *}$ & $2.25[1.60,3.16]^{* * *}$ & $1.17[0.60,2.27]$ \\
\hline$<\$ 10,000$ & $3.69[2.27,6.00]^{* * *}$ & $4.28[3.23,5.66]^{* * *}$ & $3.42[2.44,4.80] * * *$ & $2.01[0.96,4.21]$ \\
\hline \multicolumn{5}{|l|}{ Region (Urban $\dagger$ ) } \\
\hline Rural & $1.01[0.77,1.34]$ & $0.98[0.79,1.23]$ & $1.10[0.89,1.36]$ & $1.20[0.72,1.99]$ \\
\hline \multicolumn{5}{|l|}{ Maternal residence (Honolulu County $†$ ) } \\
\hline Hawai’i County & $1.17[0.80,1.72]$ & $1.04[0.74,1.45]$ & $1.13[0.86,1.47]$ & $1.22[0.64,2.34]$ \\
\hline Kaua’i County & $1.28[0.75,2.19]$ & $0.81[0.51,1.28]$ & $0.92[0.58,1.48]$ & $0.91[0.24,3.46]$ \\
\hline Maui County & $0.77[0.51,1.17]$ & $1.03[0.75,1.41]$ & $1.15[0.83,1.59]$ & $1.27[0.60,2.71]$ \\
\hline Used illicit drugs during pregnancy (Yes †) & $1.74[0.86,3.51]$ & $3.99[1.97,8.09]^{* * *}$ & $2.32[1.39,3.89] * * *$ & $0.71[0.22,2.26]$ \\
\hline
\end{tabular}

Note: Dependent variable is defined as at least one experience with one of the following nine prenatal health care access barriers: 1) I couldn't get an appointment when I wanted one; 2) I didn't have enough money or insurance to pay for my visits; 3) I had no way to get to the clinic or doctor's office; 4) I couldn't take time off from work; 5) The doctor or my health plan would not start care as early as I wanted; 6) I didn't have my Medicaid or Quest card; 7) I had no one to take care of my children; 8) I had too man other things going on; 9) I didn't want anyone to know I was pregnant.

Referent group: No physical abuse

"NHOPI” - Native Hawaiian/Other Pacific Islander; “Odds Ratio” - OR; “CI” - Confidence Interval; "PA” - Physical abuse

$\dagger$ Reference group * $\mathrm{p} \leq 0.05 * * \mathrm{p} \leq 0.01 * * * \mathrm{p} \leq 0.001$ 
Figure 1-Unadjusted and Adjusted Logistic Regression Models of Experience of Prenatal Health Care Access Barriers

Among Mothers in Hawai'i, Stratified by Race, Pregnancy Risk Assessment Monitoring System, 2004-2007

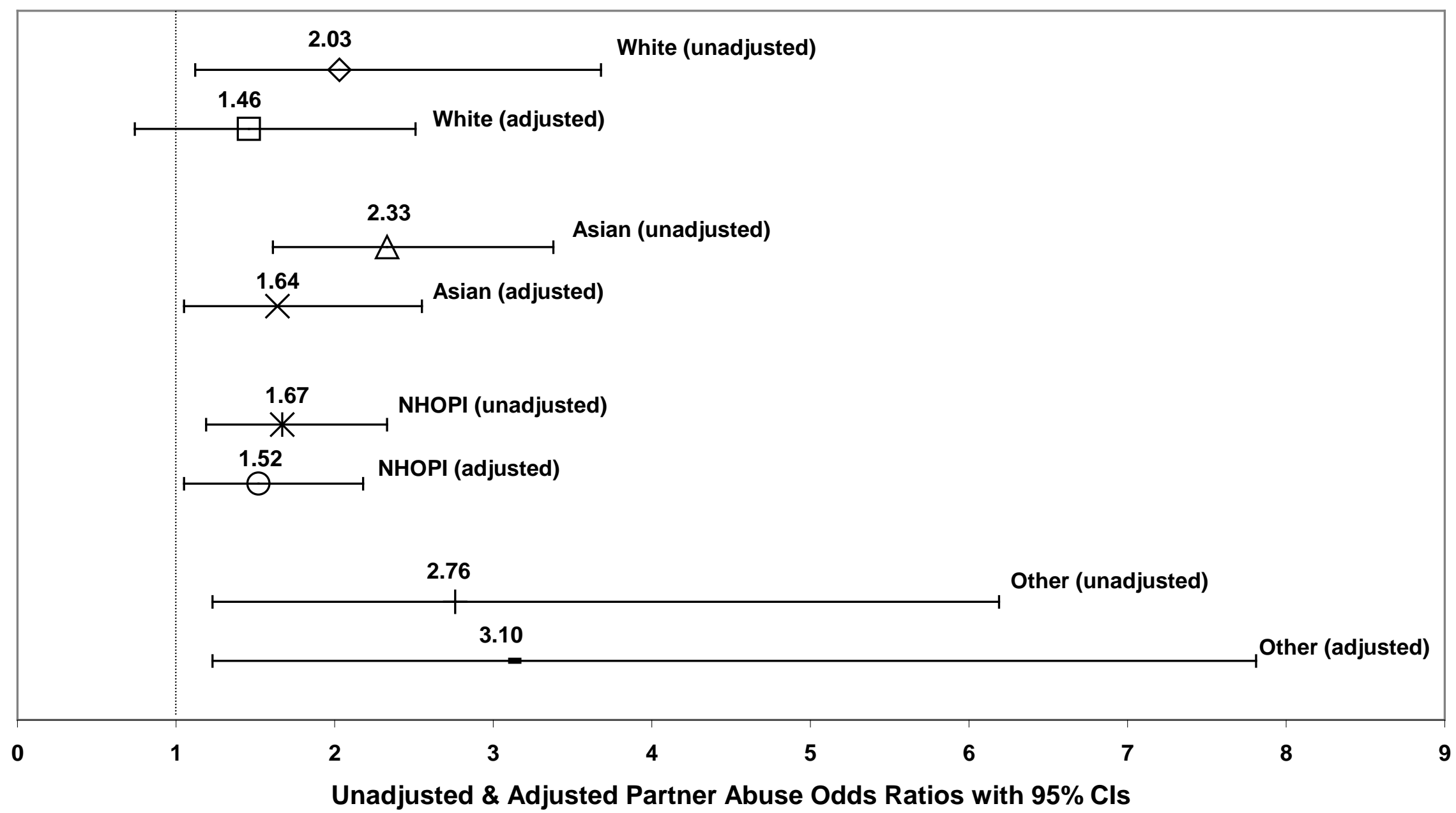

